\title{
A EXPERIÊNCIA DE IMPLANTAÇĀO DA ESCOLA DE FORMAÇĀO TÉCNICA EM SAŰDE “ENFa IZABEL DOS SANTOS" PELA SECRETARIA DE ESTADO DE SAÚDE DO RIO DE JANEIRO
}

\author{
Regina Aurora Trino Romano * \\ Milta Neide Freire Barron Torres ** \\ Marilisa Vicente Cortez *** \\ Rosemary do Nascimento Mendes ****.
}

\begin{abstract}
RESUMO - Trata-se de uma proposta de formação dirigida aos trabalhadores de nivel médio dos serviços de saúde, tendo por referência o "Projeto Larga Escala", adequado à Educação de adultos. O trabalho aborda: a ausência de investimentos na formação dos trabalhadores de saúde, dados do "Inquérito Médico Sanitário" e pesquisa "Força de Trabalho em Enfermagem". Discute o papel do setor saúde na formação de Recursos Humanos. Descreve o histórico da escola, diz de sua estrutura e recursos. Discorre acerca da concepção pedagógica, metodológica e execução descentralizada de cursos nos municípios. Conclui ser uma experiência desenvolvida e dirigida por enfermeiros, constituindo-se numa ampliaçăo de sua área de atuação.
\end{abstract}

ABSTRACT - This is a proposal of preparing aimed to medium level
workers from Health Services, having as pedagogical basis the "Great Scale
Project" adequated to grown up people's education. The work approaches:
absence of investiment in the preparing of health workers, data from
medical sanitary research and research called labor in Nursering; deals with
the role of the health branch in the preparing of Human Resources. Discuss
the pedagogical and methodological conception and talks about the
descentralized execution of courses in the many districts. It concludes to be
an experiment developed and orientated by nurses, consisting on an
enlargement of the actuation random.

\section{INTRODUÇĀO}

Ao longo desses últimos anos, o sucateamento dos serviços públicos de saúde não se limetou às instalações físicas, equipamento e à mifasagem tecnológica. Também os trabalhadores do setor saúde passaram por um processo de deterioração, pela ausência de investimentos na sua formação e atualização, ao lado da inexistência ou inadequação de planos de carreiras, cargos e salários.

Alguns estudos vêm comprovando este quadro, no que diz respeito à formação. A pesquisa AMS/IBGE $/ 87^{3}$, realizada em estabelecimentos de saúde, nos dados acerca da Força de Trabalho em Saúde, demonstrou que, no Brasil, $33,4 \%$ dos trabalhadores típicos da saúde exercem ocupações de nível elementar sem nenhuma formação específica que os habilite a prestar uma assistência à saúde, com qualidade. A mesma pesquisa demonstra que, no Estado do Rio de Janeiro, $19,12 \%$ dos trabalhadores não possuem tal habilitação profissional, excluídos deste percentual os trabalhadores de apoio administrativo.

Fazendo um corte para analisar uma parcela desta Força de Trabalho, a pesquisa realizada pelo COFEN e ABEn, acerca da Força de Trabalho em Enfermagem ${ }^{2}$, encontrou dados de composição em que os atendentes representam $63,8 \%$ do total da equipe de enfermagem no Brasil. Na situação específica do Estado do Rio de Janeiro, este segmento representa $32,8 \%$ da enfermagem.

Diante deste quadro, impõe-se que o Setor Saúde adote estratégias próprias para, a médio e longo prazos, capacitar sua força de trabalho para o exercício de suas funções.

\footnotetext{
* Enferr. :ira, Professora Auxiliar da Faculdade de Enfermagem da UERJ, Coordenadora de Desenvolvimento de Recursos Humanos da SES/RJ de abril/1989 e abril/1991.

** Enfernneira, Diretora do Departamento de Fornação da SES/RJ de abril/1989 a abril/1991.

k** Enfermeira, Diretora Geral da Escola de Formação Técnica em Saúde.

*** Enfermeira, Diretora Técnica da Escola de Formação Técnica em Saúde.
} 


\section{O Papel do Setor Saúde na Formaçāo de Recursos Humanos}

As Constituições Brasileira ${ }^{5}$ e do Estado do Rio de Janeiro ${ }^{7}$ estabelecem como competência do Sistema Único de Saúde: "ordenar a formação de recursos humanos na área da saúde". Ocorre que a formação de recursos humanos é uma atividade cuja responsabilidade não é originalmente do setor saúde. Porém, diante da necessidade de qualificar esse significativo contingente sem preparação formal, já existente nos serviços de saúde, e também em decorrência da incapacidade do setor educacional de prover, qualitativa e quantitativamente, os recursos humanos de nível médio necessários à operacionalização do setor saúde, os órgãos de recursos humanos do setor vêm buscando formas de intervir nesta situação.

Para vencer este desafio e com o apoio dos técnicos do Grupo Assessor de Recursos Humanos da Organização Panamericana de Saúde, foi recentemente implantada no Estado do Rio de Janeiro a Escola de Formação Técnica em Saúde "Enfa Izabel dos Santos", com o objetivo de promover o leque de habilitações de 1 \% e 2 o graus daquelas atividades assistenciais, de apoio diagnóstico e apoio administrativo aos serviços de saúde.

Trata-se de uma Escola voltada para a qualificação profissional dos trabalhadores dos serviços públicos de saúde do Estado do Rio de Janeiro, cidadãos social e historicamente determinados.

\section{A Escola de Formaçāo Técnica em Saúde: Histórico, Estrutura e Recursos}

A Escola de Formação Técnica em Saúde tem por desafio qualificar 12 mil trabalhadores sem habilitação profissional, que atuam no setor público de Saúde do Estado do Rio de Janeiro, dos quais 9 mil como Atendentes de Enfermagem $^{3}$. A sua concepção pedagógica teve origem no "Projeto de Formação de Pessoal de Nível Médio em Larga Escala", criado através do Acordo Interministerial MS/MEC/MT/MPAS/ OPAS, assinado em $1985^{4}$.

O primeiro espaço de aplicação desse projeto foi a "Escola de Auxiliares de Enfermagem do INAMPS", a partir de 1986, reorientando o processo de formação ali existente desde 1954. Sua conseqüência imediata foi a formação, em 1987, da primeira turma composta exclusivamente de servidores do INAMPS.

A assinatura do Convênio SUDS 01/88, apontou a necessidade de abrir o processo de formação para os servidores de todas as Instituições Públicas integrantes do Sistema Único de Saúde (SUS-RJ). Dessa forma, a experiência foi sendo aprimorada até o limite permitido pelo Parecer 477/87, que autorizou o funcionamento da Escola de Auxiliares de Enfermagem do INAMPS, em seus Núcleos de Ensino.

A reorganização do Sistema de Saúde prevista na Constituição Brasileira ${ }^{5}$ promulgada em 1988, intensificaria o Processo de Municipalização no Estado do Rio de Janeiro. Tais fatos acarretaram a necessidade de pensar em uma nova Escola que atendesse aos princípios da descentralização, do atendimento integral e da qualificação da assistência, não se perdendo de vista a concepção pedagógica do Projeto Larga Escala.

A partir desses princípios, foi criada, através de decreto do Governador do Estado, a Escola de Formação Técnica em Saúde $(\text { EFTS })^{8}$, e seu regimento e projeto de cursos foram autorizados pelo Conselho Estadual de Educação $^{10}$. Dessa forma, a Escola está apta a ministrar os cursos de Auxiliar de Enfermagem, Atendente de Consultório Dentário, Técnico de Higiene Dental, Técnico de Administração e Citotécnico, nas unidades assistenciais em todo o Estado, havendo a possibilidade de se ampliar para novos cursos.

Estruturada na Secretaria de Estado de Saúde e subordinada à Coordenadoria de Desenvolvimento de Recursos Humanos ${ }^{9}$, recebe recursos oriundos do Fundo Estadual de Saú$\mathrm{de}^{11}$, através de desembolso descentralizado, 0 que lhe garante as condiçōes materiais de funcionamento.

\section{CONCE PÇÃO PEDAGÓGICA E METODOLOGIA}

A Escola tem por finalidade ministrar cursos de qualificação profissional, pela via supletiva de ensino, à clientela já engajada na força de trabalho ou em processo de admissão nos serviços de saúde.

A opção pedagógica adotada é a da problematização. A respeito dessa pedagogia, BORDENA VE ${ }^{2}$ afirma:

"A pedagogia da problematização parte da base que em um mundo de mudanças rápidas, o importante não são os conhecimentos ou idéias nem os comportamentos corretos e fáceis que se espera, mas simo aumento da capacidade do aluno - PARTICIPANTE E AGENTE DA TRANSFORMAÇÃO SOCIAL - para detectar os problemas reais, buscar para eles soluções originais e criativas".

Trata-se de utilizar como prinć́pio pedagógico o Trabalho, não no sentido mecanicista,e sim da reflexão sobre a prática, pois é através da vivência que cada aluno traz das unidades assistenciais, que se dá a construção do conhecimento. Parte-se de um processo que possibili- 
te observar a realidade (problema), separar o que é relevante, teorizar acerca deste problema, confrontar a realidade com sua teorização para formular hipóteses de solução e, por último, aplicar à realidade (prática), segundo a concepção do método do arco de Charles Maguerez citado por BORDENAVE' 1 . Desta forma, a metodologia utilizada, por ser a mais adequada a esta proposta, é a de integração ensino-serviço, considerando-se que uma de suas metas é a qualificação da assistência de saúde prestada.

Neste processo, os alunos são o sujeito e os instrutores-supervisores, profissionais de nível superior do próprio serviço, são os facilitadores. O processo de ensino-aprendizagem é conduzido de forma flexível, tanto no plano curricular como no plano de execução, buscando-se respeitar o rítmo de cada aluno. A construção do conhecimento ocorre de uma forma reflexiva, visando preparar cidadãos que tenham a capacidade de modificar a realidade ${ }^{12}$.

Esse processo permite aos alunos adquirirem consciência dos fundamentos científicos e sociais de cada ação de saúde concomitante ao exercício das habilidades psicomotoras correspondentes e ao compromisso com uma nova ética profissional.

Os currículos aplicados nos cursos ainda são por disciplinas, porém, já bastante trabalhados no sentido de integrarem ensino e prática profissional, facilitar a interligação dos conhecimentos aprendidos em cada "disciplina" e promover a integração professor-aluno na investigação e na busca de esclarecimentos e propostas, de modo que o aluno possa buscar ativamente o seu próprio conhecimento. Esta forma de trabalhar o currículo é uma estratégia adotada de forma que tão logo se dê a conclusão dos currículos integrados, em fase de elaboração por grupos compostos pelos assessores de Recursos Humanos da OPS - "Projeto Larga Escala", a Escola estará em condições de adotá-lo.

O mecanismo de avaliação utilizado é processual, "e se inicia com o acompanhamento sistemático da evolução do educando na construção do seu conhecimento, sendo considerado como parte integrante do planejamento curricular, estando presente em todos os estágios ${ }^{6}$ de seu desenvolvimento e não apenas confinada aos seus resultados finais".

\section{Execuçāo Descentralizada}

Para alcançar o Sistema de Saúde de todo o Estado do Rio de Janeiro, a execução dos cursos é descentralizada através dos Centros de Execução Programática Descentralizada (CEPD), instalados nos serviços de saúde dos municípios ("Escola Aberta"). As diversas hajilitações são implantadas gradativamente, a partir do diagnóstico de necessidade e da existência de condições técnico-pedagógicas, respeitando-se as peculiaridade locais.

$\mathrm{O}$ apoio técnico-pedagógico ao grupo local é feito pela própria direção geral, com os coordenadores de cada área de habilitação. Este grupo técnico central se desloca aos diversos municípios em processo de supervisão permamente e afim de desenvolver estratégias de capacitação técnica e pedagógica junto ao "corpo docente" (instrutores-supervisores).

A participação dos municípios é formalizada por Termo Aditivo ao Convênio de Municipalização, onde se estabelecem claramente as responsabilidades da Secretaria de Estado de Saúde e das Prefeituras Municipais.

Assim, o processo de formação de pessoal de nível médio, promovido pela Escola, apóia e impulsiona a descentralização e a municipalização do sistema de saúde.

\section{RESULTADOS}

Durante o ano de 1990 foram implantados CEPDs nos municípios de Angra dos Reis, São Fidélis (consorciado com Santo Antonio de Pádua, Bom Jesus de Itabapoana e Miracema) e Três Rios (consorciado com Sapucaia e Pararba do Sul). Outras Secretarias Municipais, em todo o Estado, já estão promovendo o levantamento das características de sua força de trabalho, recursos físicos, materiais e humanos, para a implantação, ainda em 1991, de núcleos locais.

Atualmente estão em curso 8 (oito) turmas de Auxiliar de Enfermagem, sendo 5 (cinco) na capital e 3 (três) no interior, totalizando um quantitativo de 225 (duzentos e vinte e cinco) alunos-servidores.

Também já iniciaram sua formação tumas de Técnico de Higiene Dental e Técnico de Administração, estando em fase de preparação o curso de Técnico de Citopatologia para início no $2^{\circ}$ semestre do ano, representando no conjunto mais cinqüenta alunos.

Considerando-se a característica de "Escola Aberta", com planejamento de ter implantados (a curto e médio prazo) um Centro de Execução programática Descentralizada para cada uma das oito regiōes em que o Estado do Rio de Janeiro está dividido. Seu potencial inicial de formação é da ordem de seiscentos alunos por ano.

Em havendo a expansão para todos os cursos autorizados pelo Conselho Estadual de Educação e atendida a pretensão de cobertura para as oito regiões, torna-se possível implantar mais de um CEPD por região, o que seria de todo favorável à necessidade que os municípios têm de qualificação de pessoal de nível médio para atuar nos serviços de saúde. Tal projeto possibilitará a formação desse pessoal em larga 
escala, garantidas a qualidade e a adequação imprescindíveis para uma assistência livre de riscos à população.

\section{CONCLUSĀO}

A implantação da Escola de Formação Técnica em Saúde "Enfermeira Izabel dos Santos", tendo por base o Projeto de Formação de Pessoal de Nível Médio em Larga Escala, ainda é uma experiência em curso. Vários aspectos inovadores podem ser destacados, como a metodologia "problematizadora", o regimento inovador e a descentralização. A ressaltar ainda os baixos custos operacionais, visto que na metodologia adotada os instrutores-supervisores e os administrativos são os profissionais que já trabalham nos serviços de saúde. Estes serviços, além de sediarem o curso, servem como campos de aprendizagem.

O campo de formação de pessoal de nível médio vem demonstrando ser uma área de conhecimento atraente para os enfermeiros, motivados talvez pelas experiências anteriores, e inerentes à prática de enfermagem na área da educação. Esta experiência relatada vem sendo vivenciada por um pequeno grupo de enfermeiros do INAMPS do Rio de Janeiro que tiveram, nos últimos dois anos, inserção profissional na Secretaria de Estado de Saúde. além de um enfermeiro da SES-RJ.

A direção da Escola e a Supervisão Pedagógica são exercidas por enfermeiros que têm nos coordenadores de cursos (profissionais das áreas específicas) apoio técnico necessário à formação do leque de habilitações de nível médio de saúde.

\section{REFERÊNCIAS BIBLIOGRÁFICAS}

1 BORDENAVE, Juan Diaz. Alguns Fatores Pedagógicos. In Brasil, Ministério da Saúde. Capacitação Pedagógica para Instrutor/Supervisor - área da saúde. Brasília: Secretaria de Recursos Humanos, 1989.

2 BRASIL, Conselho Federal de Enfermagem. O Exercicio da Enfermagem nas Instituições de Saúde no Brasil: 1982/1983. Vol. I, 1985.

3 BRASIL, Instituto Brasileiro de Geografia e Estatística IBGE. Estatística da Saúde, Assistência Médico-Sanitária. Vol. 12, 1987.

4 BRASIL, Ministério da Saúde. Projeto de Formação de Pessoal de Nivel Médio em Larga Escala. Acordo MEC/M T/MS/MPAS/OPS. Brasília, 1988.

5 BRASIL, Congresso Nacional. Constituição do Brasil. Título VII, Seção II, Art. 200, 1988.

6 BRASIL, Ministério da Saúde. Capacitação Pedagogica para Instrutor/Supervisor - área da saúde. Brasília: Secretaria de Recursos Humanos, 1989.
7 ES TADO DO RIO DE JANEIRO, Assembléia Legislativa. Constituição do Estado, 1989.

8 ES TADO DO RIO DE JANEIRO, Ato do Governador. Decreto no 13.802/89. Diário Oficial, 01 de novembro de 1989.

9 ES TADO DO RIO DE JANEIRO, Secretaria Estadual de Saúde. Resolução no 542/89. Diário Oficial, 27 de novembro de 1989.

10 ESTADO`DO RIO DE JANEIRO, Conselho Estadual de Educação. Parecer n 150/90. Diário Oficial.

11 ES TADO DO RIO DE JANEIRO, Secretaria Estadual de Saúde. resolução no 567/90. Diário Oficial, 20 de abril de 1990.

12 S AN TOS, Izabel dos; Souza, Alira M.A., Galvão Ena A. Educação Médica e Salud. 22(2), 1988, pp. 191-199. 